\title{
Sosialisasi Asuransi Gempa Bumi pada Masyarakat Korban Gempa di Dusun Barong Birak Kabupaten Lombok Utara
}

\author{
Agus Sofian Eka Hidayat ${ }^{1)}$, Gilang Primajati ${ }^{2)}$ \\ 1) President University, agus.eka@president.ac.id \\ 2)Universitas Bumigora, gilangprimajati@universitasbumigora.ac.id
}

\begin{abstract}
ABSTRAK
Pengabdian ini dilaksanakan atas kerjasama antara pihak Dusun Barong Birak dan organisasi kepemudaan/kerelawanan (OKP) yang ada di Pulau Lombok. Kegiatan pengabdian sosialisasi asuransi gempa adalah sebuah kegiatan yang ditujukan bagi masyarakat desa pasca terjadinya gempa bumi di Pulau Lombok. Kegiatan pengabdian ini dilaksanakan di Dusun Barong Birak, Lombok Utara. Kegiatan ini diperuntukkan bagi anak-anak dan pemuda usia sekolah serta masyarakat dewasa dalam rangka menyebarluaskan pengetahuan tentang pengendalian risiko pada bencana gempa bumi. Pengetahuan masyarakat yang rendah terhadap manajemen bencana seperti gempa bumi, dan bagaimana mengasuransikan diri mereka terhadap adanya bencana gempa bumi menjadi suatu hal yang cukup mengkhawatirkan. Akibat, ketika bencana terjadi, hilangnya harta, rumah, akibat bencana secara finansial tidak mampu ditanggung oleh masyarakat. Melalui sosialisasi ini, diharapkan masyarakat memiliki pengetahuan tentang eksistensi asuransi gempa bumi. Metode yang digunakan dalam sosialisasi ini adalah metode diskusi kelompok dan presentasi serta diselingi game interaktif. Implikasi dari kegiatan pengabdian kepada masyarakat ini adalah mendorong masyarakat untuk mulai mengasuransikan dirinya dan asset yang dimilikinya. Selain sosialisasi asuransi, pada pengabdian ini juga diadakan sesi trauma healing dan bale belajar sebagai bentuk edukasi dan penguatan psikologis anak-anak atas bencana alam yang telah mereka alami.
\end{abstract}

Kata-kata Kunci : Sosialisasi, Asuransi, Gempa Bumi, Lombok

\begin{abstract}
This community service program was carried out in collaboration between the Barong Birak Hamlet and the youth/voluntary organization (OKP) in Lombok Island. The earthquake socialization service was done at the village community in Barong Biak, North Lombok, after the earthquake. This activity is intended for children and young people of school age and also the adult community in the context of knowledge about controlling risks in earthquake disasters. Low public knowledge of disaster management, such as earthquakes, earthquake insurance, is quite worrying. So, when a disaster occurs, the loss of property, homes, due to disasters financially can not be borne by the community. With this socialization, it is hoped that the community, especially children and youth, will understand the existence of earthquake insurance. The method used in this socialization is the method of discussion and presentation groups and interspersed with interactive games. The implication of community service is expected to be able to encourage the community to start insuring themselves and the assets they own. Furthermore, trauma healing sessions and bale learning sessions were held as a form of education and psychological reinforcement for children.
\end{abstract}

Keywords: Socialization, Insurance, Earthquake, Lombok

\section{PENDAHULUAN}

Gempa bumi yang terjadi di tahun 2018 yang menimpa masyarakat di Pulau Lombok, NTB sangatlah memprihatikan. Gempa yang sama dan pernah terjadi di tahun 1960an ini telah menghilangkan jiwa, dan harta masyarakat di Pulau Lombok, terutama 
masyarakat di Lombok Utara dan Lombok Timur. Berdasarkan data Badan Nasional Penanggulangan Bencana (BNPB) korban akibat Gempa Lombok sampai tanggal 20 Agustus 2018, korban meninggal 515 jiwa, korban luka-luka 7.145 orang, pengungsi 431.416 dan rumah rusak 73.843 (Wismabarata, 2018). Kerugian ini meliputi 5 sektor, yaitu, sektor pemukinan, infrastruktur, ekonomi produktif, sosial, dan lintas sektor. Dampak kerugian yang diakibatkan gempa bumi yang terjadi di Lombok, tidak bisa dihindarkan. Sangat disayangkan masyarakat di Pulau Lombok yang terkena dampak dari gempa bumi ini, tidak mampu mengembalikan harta benda mereka yang telah hilang. Hal ini disebabkan mayoritas masyarakat tersebut belum mengetahui adanya asuransi gempa bumi.

Sebagai negara yang berada di ring of fire, Indonesia sangat membutuhkan asuransi gempa bumi. Akan tetapi literasi warga Indonesia terhadap eksistensi asuransi masih kurang. Kejadian gempa besar akhir-akhir ini memberikan kerugian yang sangat besar baik bagi masyarakat, pengusaha, dan pemerintah. Oleh karena, sudah selayaknya eksistensi asuransi mulai diperkenalkan kepada masyarakat Indonesia secara luas, mengingat potensi becana alam gempa bumi yang memiliki frekuensi tinggi. Di negara-negara yang memiliki potensi gempa bumi yang besar seperti Jepang dan Selandia Baru, nilai pertanggungan kerugian asuransi gempa bumi cukup besar. Di Jepang, nilai kerugian yang dibayar oleh perusahaan asuransi sebesar 6-10 juta yen atau berkisar 0,785-1,3 miliar per nasabah. Hal ini telah menekan angka kerugian yang diderita oleh masyarakat Jepang. Pada tahun 2011, total kerugian yang mecakup US\$ 210 miliar, sebesar 19\% ditanggung oleh perusahaan asuransi (Hidayat, 2019). Gempa yang telah terjadi di Pulau Lombok mendorong dilakukannya sosialisasi tentang asuransi gempa bumi. Sosialisasi ini diharapkan mampu memberikan dampak positif bagi masyarakat di Lombok apabila di masa depan terjadi hal yang serupa.

Kegiatan ini dilaksanakan di Dusun Barong Birak, Desa Sambik Elen, Kecamatan Bayan, Kabupaten Lombok Utara, Lombok, NTB. Kondisi masyarakat yang ada di daerah tersebut pada pasca gempa Lombok sangat memprihatinkan. Banyak kerusakan fisik yang tampak begitu jelas, sebagian besar tergolong rusak berat. Hal ini terjadi mengingat letak desa yang langsung berbatasan dengan Gunung Rinjani dan Laut Utara Jawa, lokasi dimana titik pusat gempa terjadi. Sebagian besar masyarakat desa besar pekerjaanya adalah sebagai peladang perkebunan, penggembala sapi/kambing, dengan kondisi wilayah pegunungan dan perbukitan.

Dusun Barong Birak merupakan salah satu dusun di Desa Sambik Elen, yang letaknya paling utara di Pulau Lombok, berbatasan langsung dengan Kabupaten Lombok Timur dan berbatasan langsung dengan Laut Jawa. Hanya terdapat satu jalur akses menuju lokasi, yang melewati daerah perbukitan dengan jalan terjal dan menanjak. Dusun Barong 
Birak berjarak kurang lebih $10 \mathrm{Km}$ dari kantor desa, melewati jalan tanah yang menanjak ke arah jalan trekking Gunung Rinjani. Kondisi anak-anak muda di dusun ini minim akan keterampilan seperti Bahasa Ingris yang sangat dibutuhkan menjadi tour guide dan banyak yang putus sekolah karena keterbatasan biaya, sehingga pekerjaan mereka hanya serabutan karena kurangnya keterampilan.

Titik berat pengabdian ini adalah melakukan kerjasama antara pihak dusun Barong Birak dan organisasi kepemudaan/kerelawanan (OKP) yang ada di Pulau Lombok. Kegiatan pengabdian sosialisasi gempa adalah sebuah konsep yang ditujukan bagi masyarakat desa pasca terjadinya gempa bumi di Pulau Lombok. Kegiatan ini diperuntukan bagi anak-anak dan pemuda usia sekolah dalam rangka pengetahuan tentang mengendalikan risiko pada becana gempa bumi. Pengetahuan masyarakat yang rendah terhadap manajemen bencana seperti gempa bumi, dan bagaimana mengasuransikan diri mereka terhadap adanya bencana gempa bumi yang akan diprioritaskan. Sosialisasi asuransi gempa dilaksanakan kepada kalangan yang secara ekonomi sudah cukup baik dan menggunakan asuransi yang telah ada dari perusahaan asuransi.

Selain itu dilakukan pendirian sebuah Bale (Rumah) Terpadu untuk masyarakat yang digunakan sebagai kelas inspirasi, sehingga bertambahnya motivasi bersekolah, akses informasi, ilmu, wawasan, keahlian dan keterampilan bagi pemuda di desa tersebut. Bale Terpadu dikhususkan sebagai konsep/model pendidikan dan pelatihan yang mengedepankan semangat didik (trauma healing) bukan dalam artian membangun fasilitas fisik. Pemulihan kondisi piskologis para penyintas diperlukan keterlibatan seluruh pihak dalam hal ini, namun penulis percaya bangsa Indonesia adalah bangsa yang kuat dan memiliki keihklasan hati dalam menerima setiap musibah yang menimpanya (Taibe, 2019).

Harapan dari kegiatan pengabdian ini adalah mampu meningkatkan kesadaran akan pentingnya berasuransi, mengurangi trauma jangka pendek dan jangka panjang akibat gempa, dan menambah pemahaman masyarkat akan pendidikan kebencanaaalaman khususnya gempa bumi. Selain itu, trauma di masyarakat, anak-anak khususnya, dapat hilang dengan cepat. Sebab trauma akan menjadi beban di masa depan, apabila tidak diselesaikan secara cepat.

\section{METODE PELAKSANAAN}

Metode pelaksanaan program pengabdian masyarakat ini adalah dengan menggunakan metode transfer ilmu secara langsung dari relawan kepada anak-anak usia sekolah secara langsung. Transfer ilmu yang disampaikan melalui metode presentasi, diskusi dan dilanjutkan dengan games untuk meningkatkan pengetahuan. Pada tahapan awal kegiatan ada beberapa hal yang dilakukan, yaitu tahapan persiapan program yang 
terdiri atas: 1) survei tempat pelaksanaan kegiatan, 2) penyelesaian administrasi/ijin surat menyurat, 3) pengumpulan buku-buku bacaan, alat peraga kelas motivasi trauma healing dan pemantapan games yang memberikan motivasi menambah semangat belajar kepada relawan, 4) simulasi dan praktik ke pihak relawan (lihat Gambar 1).

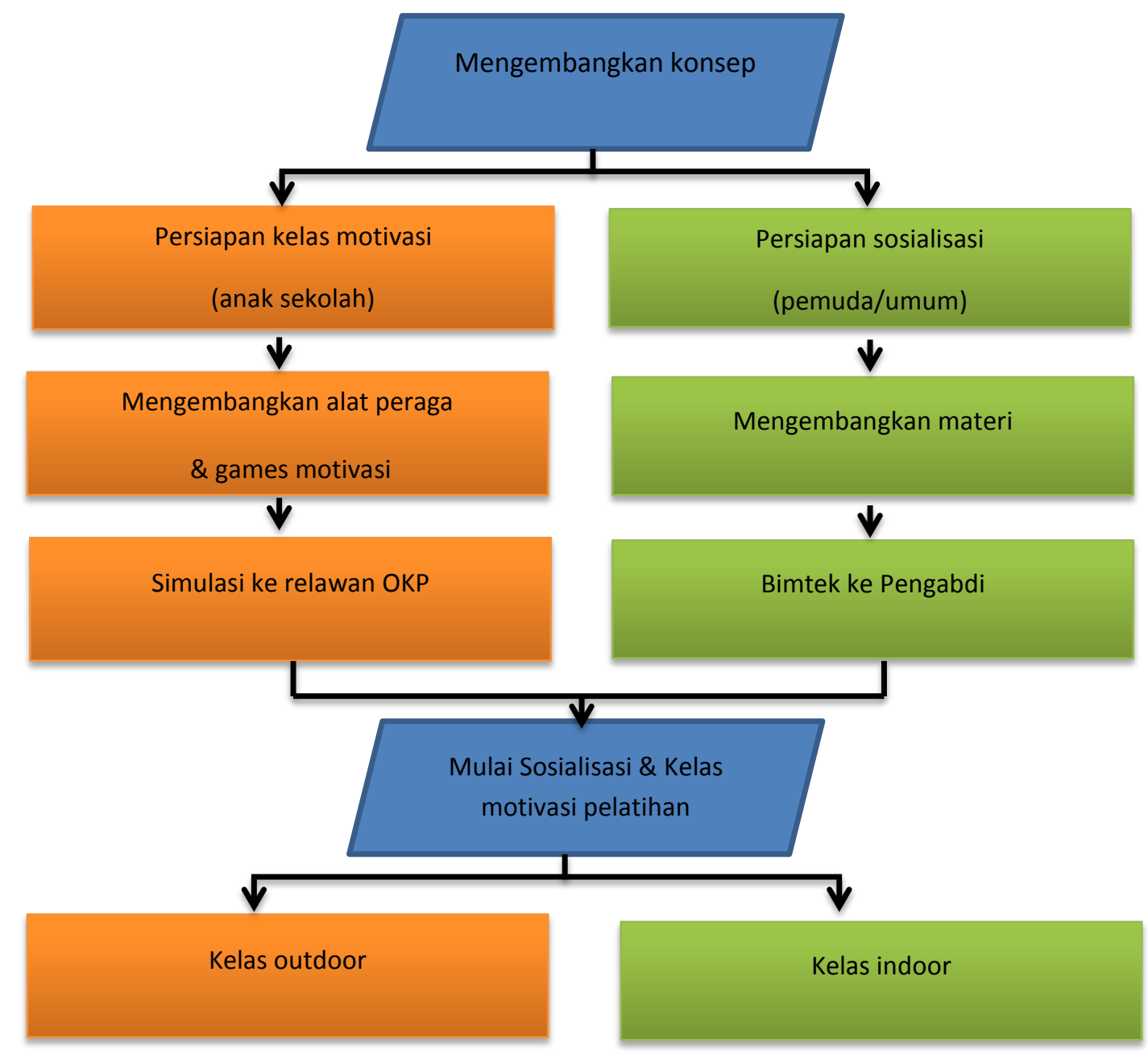

Gambar 1.

Skema Pelaksanaan

Kegiatan pengabdian di Dusun Barong Birak dilakukan dengan metode pelaksanaan tatap muka yaitu yang pertama adalah sosialisasi asuransi gempa dan kelas bale terpadu menggunakan metode transfer ilmu secara langsung dari akademisi/relawan/mahasiswa kepada sasarannya dan langsung melaksanakan praktek atau pengajaran dengan menggunakan peraga, secara manual maupun menggunakan perangkat teknologi. Kegiatan pengabdian masyarakat ini dilaksanakan setelah semua perijinan dan persiapan peralatan peraga, materi untuk kegiatan sudah selesai dilakukan. Kegiatan dilaksanakan di aula, tanah lapang dan halaman Dusun Barong Birak Desa Sambik Elen. Dalam pelaksanaan, peserta dibagi menjadi dua kelompok yaitu kelas anak-anak usia sekolah dasar dan kelas 
remaja/pemuda. Setiap kelompok menjalani kelas di waktu yang berbeda. Waktu yang digunakan adalah setiap akhir pekan yaitu Sabtu/Minggu. Hari Sabtu dimulai pukul 16.00 WITA dan hari Minggu dilaksanakan pada pagi hari mulai jam 09.00 pagi. Pelatihan bagi pemuda dilaksanakan pada hari Sabtu jam 16.00, karena itu adalah waktu senggang mereka setelah pulang beraktifitas di sawah/kebun. Metode untuk pelatihan ini menggunakan metode kelas yang dibimbing oleh relawan dan pengabdi sendiri.

Untuk kelas motivasi, materi disampaikan dengan menggunakan alat peraga baik digital maupun dengan klasikal. Di setiap kelas disampaikan sisipan nilai-nilai pendidikan dan motivasi baik secara langsung maupun tak langsung. Di setiap kegiatan juga ada permainan seru yang mengasah kerjasama, kekompakan, keberanian, kecerdasan dan ketangkasan yang nantinya dapat menghilangkan ingatan peserta tentang trauma yang dialami. Selain itu juga ada kuis inspiratif dari relawan dan pengabdian untuk mendapatkan berbagai macam hadiah-hadiah yang menarik dan menghibur.

Evaluasi diadakan setiap kegiatan yang telah dilakukan mengingat kegiatan ini diadakan selama sebulan setiap akhir pekan. Evaluasi tersebut guna mencari solusi jika terjadi hambatan dan kekurangan selama dalam kegiatan yang telah dilakuan sehingga kegiatan selanjutnya bisa berjalan lebih baik lagi. Dengan demikian dapat diketahui sejauh mana kemampuan para peserta terhibur lalu melupakan segala trauma yang sedang dialami dan bersemangat serta capaian keahlian kegiatan pelatihan.

\section{HASIL DAN PEMBAHASAN}

Dusun Barong Birak adalah salah satu dusun yang terletak di Desa Sambik Elen Kecamatan Bayan kabupaten Lombok Utara dengan jumlah kepala keluarga sebanyak 221 , dengan jumlah pemuda sebanyak 40 orang. Masyarakat yang mengikuti kegiatan kelas motivasi berjumlah 30 orang (lihat Tabel 1). Sebaran pemuda menurut pendidikan adalah masih bersekolah di tingkat Sekolah Menengah Atas (SMA) sebanyak 10 orang dari 20 orang yang berumur 15-18 tahun dan sisanya tidak bersekolah. Hal inilah yang melatarbelakangi kami untuk membangun Bale Terpadu dan memberikan kelas inspirasi dan pelatihan/keahlian pasca gempa bagi. Sedangkan relawan-relawan yang ikut dalam kegiatan ini merupakan gabungan antara berbagai macam elemen masyarakat dan profesi, yaitu dosen, atlet, perawat dokter, profesional, pegawai negri sipil, dan pengusaha (lihat Tabel 2). 
Tabel 1.

Daftar Peserta Pelatihan Sosialisasi

\begin{tabular}{|c|c|c|c|}
\hline \multirow{2}{*}{ No } & \multicolumn{3}{|c|}{ Kelas Pelatihan } \\
\hline & Nama Pemuda & Umur & Keterangan \\
\hline 1 & Irwan & 15 & Masih Sekolah \\
\hline 2 & Cahyadi & 20 & Tidak Bersekolah \\
\hline 3 & Ari & 17 & Masih Sekolah \\
\hline 4 & Doyok & 18 & Tidak Bersekolah \\
\hline 5 & Alfariki & 19 & Tidak Bersekolah \\
\hline 6 & Ucuop & 20 & Tidak Bersekolah \\
\hline 7 & Wahyu & 20 & Tidak Bersekolah \\
\hline 8 & Hendara & 17 & Tidak Bersekolah \\
\hline 9 & Dahrim & 18 & Masih Sekolah \\
\hline 10 & Aan & 13 & Tidak Bersekolah \\
\hline 11 & Said & 15 & Masih Sekolah \\
\hline 12 & Bahri & 20 & Tidak Bersekolah \\
\hline 13 & Saipul & 17 & Tidak Bersekolah \\
\hline 14 & Tila & 16 & Masih Sekolah \\
\hline 15 & Tari & 18 & Tidak Bersekolah \\
\hline 16 & Eka & 16 & Tidak Bersekolah \\
\hline 17 & Kahfi & 15 & Masih Sekolah \\
\hline 18 & Mar & 15 & Masih Sekolah \\
\hline 19 & Faiz & 16 & Masih Sekolah \\
\hline 20 & Yusron & 18 & Tidak Bersekolah \\
\hline 21 & Ali & 19 & Tidak Bersekolah \\
\hline 22 & Ahmad B & 18 & Tidak Bersekolah \\
\hline 23 & Ili & 18 & Tidak Bersekolah \\
\hline 24 & Yusuf & 16 & Tidak Bersekolah \\
\hline 25 & Idris & 15 & Masih Sekolah \\
\hline 26 & Imam & 14 & Tidak Bersekolah \\
\hline 27 & Rian & 18 & Tidak Bersekolah \\
\hline 28 & Hafiz & 16 & Masih Sekolah \\
\hline 29 & Yaq & 17 & Tidak Bersekolah \\
\hline 30 & Rini & 15 & Tidak Bersekolah \\
\hline
\end{tabular}


Tabel 2.

Daftar Relawan Sosalisasi dan Kelas Motivasi

\begin{tabular}{|c|c|c|}
\hline \multirow{2}{*}{ No } & \multicolumn{2}{|c|}{ Kelas Motivasi } \\
\hline & Nama Relawan & Profesi \\
\hline 1 & Agus Sofian Eka H, M.Sc & Dosen \\
\hline 2 & Gilang Primajati, S.Si.,M.Sc & Dosen \\
\hline 3 & Khairul Anam, S.Pd.,M.Fis & Atlet \\
\hline 4 & Arlan Rahmadi, S.Kep & Perawat \\
\hline 5 & dr.Siti Rosida & Dokter \\
\hline 6 & $\begin{array}{l}\text { Dedet Dzeltauzzalam, } \\
\text { SIP.,MM }\end{array}$ & PNS Kota \\
\hline 7 & Saiful Bahri,ST & BPD Desa \\
\hline 8 & dr.Abi azhar & Dokter \\
\hline 9 & Yuniar Andini ,S.Pd & Guru \\
\hline 10 & Irwan Cahyadi,MM & Dosen \\
\hline 11 & Armei Rapiudin & Ahli tata kota \\
\hline 12 & Akbar Habibi & $\begin{array}{l}\text { Pengusaha } \\
\text { properti }\end{array}$ \\
\hline 13 & Baiq Rian, S.Ikom & Profesional \\
\hline 14 & Winda, S.farm.,Apt & Apoteker \\
\hline 15 & Salman Alfarisi,S.com & progremer \\
\hline 16 & Ervina, S.Si & Laboran \\
\hline 17 & Ahmad Zuli Amrullah, M.Eng & Dosen/programmer \\
\hline 18 & Ahmad, M.Pd & Dosen \\
\hline
\end{tabular}

Kelas motivasi adalah suatu konsep pendidikan informal yang kami gagas sebagai penunjang untuk meningkatkan semangat peserta didik pasca gempa agar memiliki mental yang kuat untuk merajut kembali cita-cita membangun masa depan. Peserta kelas ini diajari bagaimana cara berani bermimpi dan mewujudkannya (lihat Gambar 2). Cara yang kami gunakan adalah mengundang relawan-relawan yang sudah berhasil dari berbagai latar belakang profesi agar peserta didik secara langsung dapat melihat dan merasakan atmosfer apa yang mereka cita-citakan. 


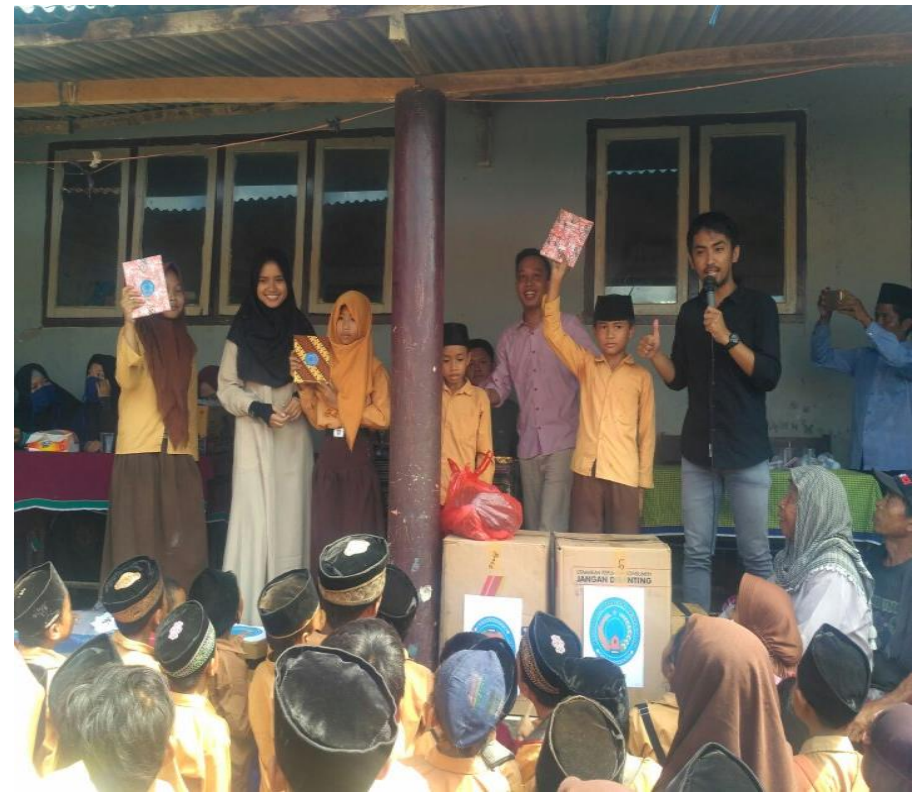

Gambar 2.

Kelas Motivasi untuk Siswa Sekolah Dasar

Tidak hanya peserta didik, sambutan masyarakatpun sangat luar biasa. Perangkat desa mendukung kegiatan ini. Banyak doorprize yang disiapkan di acara pembukaaan agar acara semakin semarak dan meriah (lihat Gambar 3).

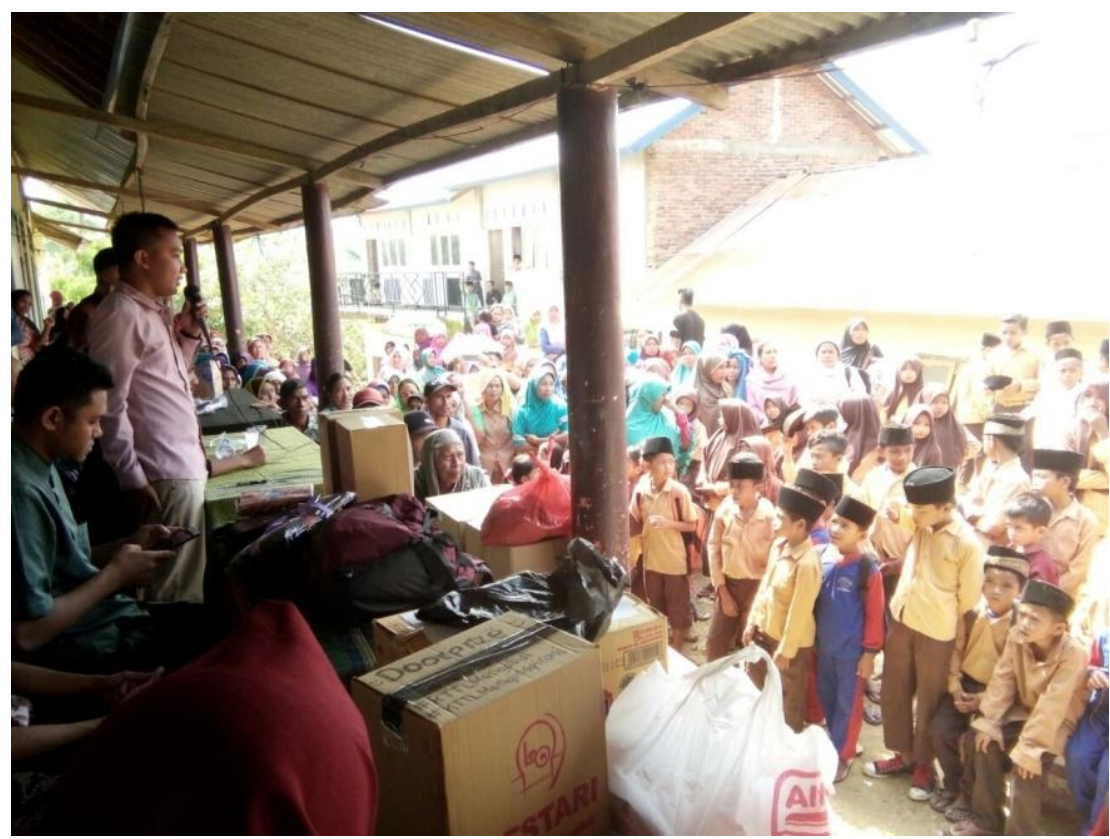

Gambar 3.

Antusiasme Masyarakat

Kegiatan selanjutnya merupakan kegiatan inti dari pengabdian kepada masyarakat ini, yaitu sosialisasi asuransi gempa kepada masyarakat desa. Kegiatan ini mengundang 
pemuda dan juga masyarakat desa yang ada terkena dampak gempa baik secara materi dan non-materi. Pada sesi ini dijelaskan bagaimana pentingnya untuk mengasuransikan diri, dengan membeli asuransi gempa bumi. Pada kesempatan ini, dijelaskan pentingnya asuransi gempa bumi, dan apa dampak positif yang bisa diberikan oleh pihak asuransi kepada para korban-korban yang mengalami bencana alam seperti gempa bumi. Animo masyarakat dalam mengikuti kegiatan sosialisasi gempa bumi sangatlah tinggi (lihat Gambar 4). Hal ini dapat dilihat dari banyaknya partisipasi dari masyarakat untuk ikut dalam pertemuan yang telah direncanakan sebelumnya. Dalam kegiatan ini, diketahui bahwa masyarakat ini tidak tahu tentang adanya asuransi gempa bumi. Setelah mendapatkan pengetahuan tersebut, tidak banyak masyarakat yang mau mencoba untuk mendaftarkan diri mereka dalam mengikuti asuransi bencana gempa bumi. Akan tetapi, sebagian besar belum mampu mengikutinya karena keterbatasan ekonomi saat ini.

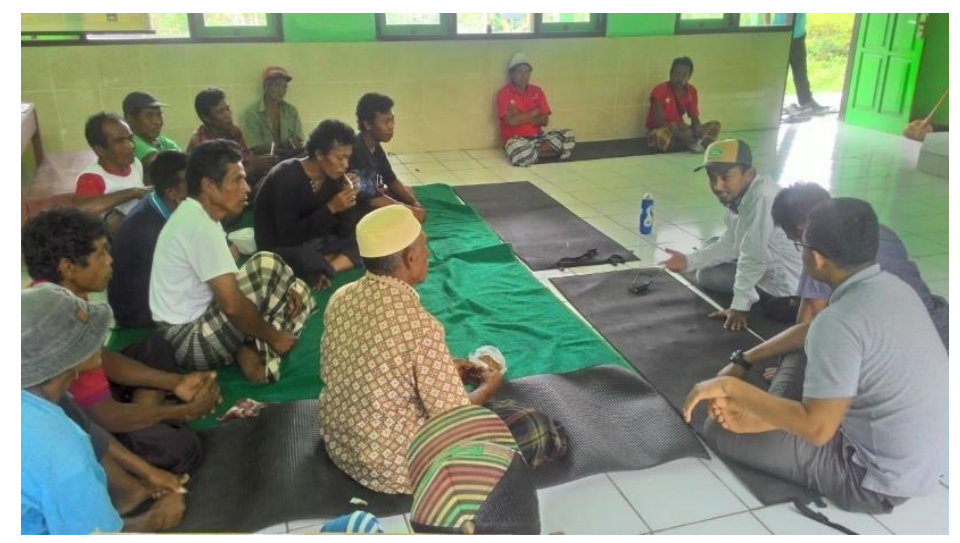

Gambar 4.

Sosialisasi Pentingnya Asuransi Gempa Bumi

Untuk menutup kegiatan sosialisasi dan kelas motivasi ini, diakhir kegiatan dilakukan pembagian hadiah kepada peserta, sebagai ucapan terimakasih telah mengikuti kegiatan yang sangat mengasikkan ini. Di hari terakhir ada beberapa orang tua yang ikut masuk ke kelas untuk mendengarkan atau sekedar melihat anak-anak mereka bermain.

\section{KESIMPULAN}

Berdasarkan kegiatan yang telah dilakukan, dapat disimpulkan bahwa asuransi gempa bumi perlu diberikan oleh pemerintah sebagai jaminan untuk menjaga resiko yang tidak diinginkan, terlebih untuk daerah-daerah rawan bencana gempa. Materi sosialisasi yang diberikan oleh para relawan dapat diserap dengan penuh kegembiraan. Akan tetapi tidak semua masyarakat mau dan mampu untuk mengikuti asuransi gempa bumi sebab terbatasnya kondisi ekonomi yang mereka hadapi saat ini. Kelas motivasi dapat menjadi 
suatu konsep informal yang dapat membantu masyarakat untuk mengatasi trauma gempa baik jangka pendek maupun jangka panjang. Dengan adanya kelas motivasi ini, anak-anak mulai mampu menghilangkan trauma yang mereka alami ketika datang bencana gempa bumi.

\section{REFERENSI}

Hidayat, A.S. E. (2019) . Asuransi Gempa BumiUrgensi Asuransi Gempa Bumi bagi Masyrakat di Negara Ring of Fire. Retrieved from https://datapolis.id/urgensiasuransi-gempa-bumi-bagi-masyrakat-di-negara-ring-of-fire/

Taibe., P. (2019). Membangun Kembali Asa yang Hilang Melalui "Trauma Healing". Retrieved from https://www.kompasiana.com/studitiongkok/ 5c3ee90bc112fe520d2f48b8/membangun-kembali-asa-yang-hilang-melalui-traumahealing?page=all

Wismabarata, M., H. (2018). 5 Fakta Terbaru Gempa Lombok, 515 Korban Meninggal hingga Kerugian Rp 7,7 Triliun. online. Retrieved from dari https://regional.kompas.com/read/2018/08/21/19041711/5-fakta-terbaru-gempalombok-515-korban-meninggal-hingga-kerugian-rp-77 